\title{
Incretin based drugs and risk of acute pancreatitis in patients with type 2 diabetes: cohort study
}

\author{
(c) $1(1) \circledast$ OPEN ACCESS
}

\author{
Jean-Luc Faillie pharmacoepidemiology fellow ${ }^{123}$, Laurent Azoulay assistant professor ${ }^{14}$, Valerie \\ Patenaude statistician ${ }^{1}$, Dominique Hillaire-Buys assistant professor ${ }^{35}$, Samy Suissa professor \\ and director ${ }^{16}$
}

${ }^{1}$ Centre for Clinical Epidemiology, Lady Davis Institute, Jewish General Hospital, Montreal, Quebec, Canada; ${ }^{2}$ Department of Pharmacoepidemiology, INSERM U1027, Faculty of Medicine, Paul Sabatier University, Toulouse, France; ${ }^{3}$ Department of Medical Pharmacology and Toxicology, Montpellier University Hospital, Montpellier, France; ${ }^{4}$ Department of Oncology, McGill University, Montreal, Quebec, Canada; ${ }^{5}$ INSERM U1058, Faculty of Medicine, University of Montpellier 1, Montpellier, France; ${ }^{6}$ Department of Epidemiology, Biostatistics and Occupational Health, McGill University, Montreal, Quebec, Canada

\begin{abstract}
Objectives To determine whether the use of incretin based drugs, compared with sulfonylureas, is associated with an increased risk of acute pancreatitis.

Design Population based cohort study.

Setting 680 general practices in the United Kingdom contributing to the Clinical Practice Research Datalink.

Participants From 1 January 2007 to 31 March 2012, 20748 new users of incretin based drugs were compared with 51712 users of sulfonylureas and followed up until 31 March 2013.

Main outcome measures Cox proportional hazards models were used to estimate hazard ratios and $95 \%$ confidence intervals for acute pancreatitis in users of incretin based drugs compared with users of sulfonylureas. Models were adjusted for tenths of high dimensional propensity score (hdPS).

Results The crude incidence rate for acute pancreatitis was 1.45 per 1000 patients per year ( $95 \%$ confidence interval 0.99 to 2.11 ) for incretin based drug users and 1.47 (1.23 to 1.76) for sulfonylurea users. The rate of acute pancreatitis associated with the use of incretin based drugs was not increased (hdPS adjusted hazard ratio: $1.00,95 \%$ confidence interval 0.59 to 1.70 ) relative to sulfonylurea use.
\end{abstract}

Conclusions Compared with use of sulfonylureas, the use of incretin based drugs is not associated with an increased risk of acute pancreatitis. While this study is reassuring, it does not preclude a modest increased risk, and thus additional studies are needed to confirm these findings.

\section{Introduction}

Glucagon-like peptide-1 (GLP-1) analogues and dipeptidyl peptidase-4 (DPP-4) inhibitors are new classes of antidiabetes drugs. These drugs stimulate insulin secretion according to glucose concentration and inhibit glucagon secretion by either direct binding to the GLP-1 receptor or by inhibiting the degradation of endogenous GLP- $1 .{ }^{1}$ While these drugs have been shown to have a modest effect on haemoglobin A1c (HbA1c), with favourable effects on weight and a reduced risk of hypoglycaemia, ${ }^{2}$ there have been safety concerns regarding their effects on the pancreas. Specifically, analyses of adverse event databases have associated incretin based drugs with acute pancreatitis ${ }^{3-6}$ resulting in pharmacovigilance alerts ${ }^{7-9}$ and the addition of this possible adverse event on product monographs. ${ }^{10-14}$ Currently, there are continued concerns, partly due to the conflicting results of the observational studies conducted to date. ${ }^{15-23}$ As a result, the European Medicines Agency and the US Food and Drug Administration have called for additional studies to assess this potential risk..$^{24}$

Given the increasing number of patients being prescribed incretin based drugs and concerns regarding their safety, we conducted a large population based study to determine whether the use of GLP-1 analogues and DPP-4 inhibitors, when compared with sulfonylureas, a second line treatment for type 2 diabetes, is associated with an increased risk of acute pancreatitis. 


\section{Methods \\ Data sources}

This study was conducted with the UK Clinical Practice Research Datalink (CPRD) and hospital episodes statistics (HES) database. The CPRD has medical information on more than 13 million individuals across 680 general practices, with similar age and sex distributions to those reported by the UK National Population Census. ${ }^{26}$ Information collected includes demographic characteristics, diagnoses, and drug prescriptions issued by the general practitioners. Diagnoses and procedures are coded with the Read classification and prescriptions are coded according to the UK Prescription Pricing Authority Dictionary. Data collected in the CPRD have been validated and deemed to be of high quality. ${ }^{27}$ Since 1997, the HES database collects information on dates of hospital admissions, discharge diagnoses (coded with ICD-10 (international classification of diseases, 10th revision)), and procedures (coded using the Office of Population Censuses and Surveys classification of interventions and procedures, 4th version).

\section{Study population Base cohort}

From the CPRD population, we identified a base cohort consisting of all patients aged at least 18 newly treated with a non-insulin antidiabetes drug (metformin, sulfonylureas, prandial glucose regulators, thiazolidinediones, acarbose, DPP-4 inhibitors, and GLP-1 analogues) from 1 January 1988 to 31 March 2013. All patients were required to have at least six months of "up to standard" medical history in the CPRD before their first non-insulin prescription.

\section{Subcohorts of patients treated with incretin based drugs and sulfonylureas}

Within the base cohort defined above, we identified all patients who were newly prescribed incretin based drugs (GLP-1 analogues: exenatide and liraglutide; DPP-4 inhibitors: sitagliptin, saxagliptin, vildagliptin, linagliptin), either in monotherapy or combination, during the study period. These patients were compared with patients prescribed sulfonylureas, either in monotherapy or combination, as of 2007-that is, after the first DPP-4 inhibitor was licensed in the UK. Thus, cohort entry for both exposure groups was defined as the first prescription received as of 2007 . We excluded patients previously diagnosed with pancreatic cancer, those who had undergone a pancreatectomy, those with a history of pancreatic injury or congenital defects of the pancreas, as well as those with cystic fibrosis, lupus, polycystic ovarian syndrome, and those who had undergone bariatric (bypass) surgery (as these surgeries have been associated with increased levels of endogenous GLP-1 $)^{28}$ at any time before cohort entry. All patients meeting the study inclusion criteria were followed until a diagnosis of acute pancreatitis (recorded in either the CPRD (on the basis of Read codes) or HES database (ICD-10 codes: $\mathrm{K} 85.0, \mathrm{~K} 85.1, \mathrm{~K} 85.2, \mathrm{~K} 85.3$, K85.8, K85.9 in primary or secondary position)), death from any cause, end of registration with the general practice, or the end of the study period (31 March 2013), whichever came first.

\section{Exposure definition}

We used an "as treated" definition of exposure for patients in the incretin based drug and sulfonylurea groups. For this definition, we considered patients as continuously exposed if the duration of one prescription overlapped with the prescribing of the subsequent prescription. In the event of non-overlap, we allowed for a 30 day grace period between two successive prescriptions. Termination of treatment was therefore defined by either the absence of a new prescription by the end of a 30 day grace period or a switch to insulin, whichever came first.

\section{Statistical analysis}

We used descriptive statistics to summarise the characteristics of users of incretin based drugs and sulfonylureas. Person time at risk was measured from cohort entry (that is, first prescription of an incretin based drug or sulfonylurea on or after 2007) to time of event or end of exposure for the as treated analysis. We calculated crude incidence rates, with confidence intervals based on the Poisson distribution, by dividing the number of patients with acute pancreatitis over the person time at risk for each exposure group.

We constructed Kaplan-Meier curves for each exposure group to compare the cumulative incidence of acute pancreatitis. Cox proportional hazards models were used to estimate hazard ratios and $95 \%$ confidence intervals for acute pancreatitis associated with the use of incretin based drugs compared with the use sulfonylureas based on the as treated exposure definition. We also conducted two secondary analyses. In the first, we evaluated whether the risk varied with duration of use. For this analysis, we calculated hazard ratios for three time intervals of use (0-1 year, 1-2 years, >2 years). In the second, we assessed whether the risk varied between men and women. We could not conduct separate analyses for patients who used DPP-4 inhibitors compared with GLP-1 analogues as the latter group was too small.

All models were adjusted for tenths of high dimensional propensity score (hdPS), which is a method that empirically selects covariates based on their prevalence and potential for confounding. ${ }^{29}$ For each patient we used multivariate logistic regression to calculate a propensity score, which was the probability of being exposed to incretin based drugs compared with sulfonylureas, conditional on 500 empirically identified and 13 predefined covariates measured at cohort entry. We estimated the empirical covariates from five data dimensions (drug prescriptions, procedures, diagnoses, disease history, and administrative information), while the predefined covariates consisted of age, sex, duration of treated diabetes (defined as the time between a first ever non-insulin prescription and cohort entry), $\mathrm{HbAlc}$, excessive alcohol use (based on diagnoses for alcohol related disorders, such as alcoholism, alcoholic cirrhosis of the liver, alcoholic hepatitis, and hepatic failure), body mass index (BMI), smoking status, history of gallstones, and use of antidiabetes drugs in the year before cohort entry (metformin, sulfonylureas, thiazolidinediones, insulins, and other agents). In addition to the tenths of hdPS, we adjusted the models for calendar year of cohort entry. Variables with missing data were coded with an "unknown" category. ${ }^{30}$ Overall, there was good overlap in the propensity score distributions between the exposure groups, and the hdPS model had excellent discrimination (C statistic 0.89). ${ }^{31}$

\section{Sensitivity analyses}

We also performed four sensitivity analyses to assess the robustness of the results. Firstly, we repeated the analyses using an "intention to treat" exposure definition, which was defined by considering patients continuously exposed from cohort entry until the end of follow-up, regardless of treatment terminations or switches to other antidiabetes drugs. Secondly, we repeated the primary analysis by matching each user of an incretin based 
drug with up to two users of a sulfonylurea on the nearest hdPS score using a greedy matching algorithm. ${ }^{32}$ Thirdly, as some people in both the incretin based drug and sulfonylurea groups had a history of sulfonylurea use, we conducted a sensitivity analysis by stratifying patients on this history of use. Finally, to deal with uncertainties related to the choice of our sulfonylurea reference group, we repeated the primary analyses in an identical fashion comparing users of incretin based drugs with users of insulins and with users of metformin. All analyses described above were conducted with SAS, version 9.3 (SAS Institute, Cary, NC).

\section{Results}

We identified 153983 users of antidiabetes drugs after 2007, which included 20748 users of incretin based drugs and 51712 users of sulfonylureas (fig $1 \Downarrow$ ). The mean time the patients were receiving treatment was 1.4 years, corresponding to 99497 person years of follow-up. We identified 146 cases of acute pancreatitis, generating an overall incidence rate of 1.47 per 1000 person years.

Table 1 shows the characteristics of the incretin based drug and sulfonylurea users $\Downarrow$. Compared with sulfonylurea users, incretin based drug users were younger, more likely to be obese, had longer durations of treated diabetes, higher concentrations of $\mathrm{HbAlc}$, and were more likely to use antidiabetes drugs in the year before cohort entry.

Table $2 \Downarrow$ presents the results of the primary as treated analysis. The mean (SD) time patients were taking treatment was 0.9 (0.9) and 1.6 (1.6) years for incretin based drug users and sulfonylurea users, respectively. Overall, $13.5 \%$ in the incretin based drug group and $28.7 \%$ in the sulfonylurea group were prescribed these drugs as monotherapy during follow-up, while $75.6 \%$ and $67.3 \%$ were prescribed them concurrently with combinations containing metformin, respectively.

The crude incidence rate of acute pancreatitis (per 1000 person years) in incretin based drug users was similar to the rate in sulfonylurea users $(1.45,95 \%$ confidence interval 0.99 to 2.11 , and $1.47,1.23$ to 1.76 , respectively). Kaplan-Meier curves for incretins and sulfonylureas were not significantly different from each other ( $\log$ rank $\mathrm{P}=0.36$; fig $2 \Downarrow$ ). In the hdPS adjusted model, the use of incretin based drugs was not associated with an increased risk of acute pancreatitis (hazard ratio 1.00, 95\% confidence interval 0.59 to 1.70 ).

Table $3 \Downarrow$ presents the results of secondary analyses. The risk of acute pancreatitis did not vary with duration of use of incretin based drugs. When stratified by sex, the hazard ratio was higher in men than in women but did not reach significance.

\section{Sensitivity analyses}

When we used an intention to treat definition of exposure, results were similar to those generated with the as treated definition (table A in appendix). Likewise, the results were similar after we matched on hdPS scores (table B in appendix). Overall, stratification on history of sulfonylurea use before cohort entry did not result in significant associations, although the hazard ratio was higher among patients with such a history (table $\mathrm{C}$ in appendix). Finally, in the analyses comparing incretin based drug users with users of insulin and metformin, we noted important yet expected differences. Specifically, duration of treated diabetes was longer in insulin users, while the opposite was the case for metformin users (mean durations 6.1 and 1.7 years, respectively; tables D and $\mathrm{E}$ in appendix). In the hdPS adjusted models, when compared with insulins, the use of incretin based drugs was not associated with a significant risk of acute pancreatitis, with the hazard ratio under the null value $(0.79,95 \%$ confidence interval 0.19 to 3.35 ; table $\mathrm{F}$ in appendix). A similar non-significant association was observed when we compared incretins with metformin, although the hazard ratio was numerically increased (1.52, 0.83 to 2.81; table $\mathrm{G}$ in appendix).

\section{Discussion}

The results of our cohort study do not support the hypothesis of an increased risk of acute pancreatitis associated with the use of incretin based drugs compared with sulfonylureas in people with type 2 diabetes. We did not observe any variation with duration of use or after stratification by sex, with all point estimates close to the null value. Moreover, the results remained consistent after we performed several sensitivity analyses. Nonetheless, given the rarity of the outcome, this study does not preclude a possible modest increased risk of acute pancreatitis associated with incretin based drugs.

\section{Comparison with other studies}

The potential risk for acute pancreatitis associated with incretin based drugs was raised after signals issued from pharmacovigilance systems. ${ }^{3-9}$ A hypothesis for this possible association relates to pancreatic enlargement and duct occlusion by proliferation of duct cells, ${ }^{33}{ }^{34}$ although this has been disputed. ${ }^{35}$ Our null results are consistent with the conclusions of two recent meta-analyses of randomised controlled trials on the effects of DPP-4 inhibitors (odds ratio $0.89,95 \%$ confidence interval 0.32 to 2.49$)^{36}$ and GLP-1 analogues (1.01, 0.37 to $2.76)^{37}$ on acute pancreatitis, as well as with eight ${ }^{15-22}$ of the nine ${ }^{23}$ observational studies conducted to date. In two studies, the use of exenatide and sitagliptin for up to one year was not associated with increased risks of acute pancreatitis (rate ratio 1.0 (95\% confidence interval 0.6 to 1.7$)$ and 1.0 (0.5 to 2.0), respectively). ${ }^{15}$ For past users of exenatide, however, a significant increased risk was observed $(2.8,1.6$ to 4.7$) .{ }^{15}$ Subsequently, five other observational studies did not observe any significant increased risk of acute pancreatitis associated with the use of incretin based drugs. ${ }^{17-22}$ These results are also consistent with those of recent randomised controlled trials, in which no increased risk of acute pancreatitis was noted with saxagliptin and alogliptin. ${ }^{38}{ }^{39}$ Our results, however, contrast with those of a recent case-control study, ${ }^{23}$ in which current and recent use (between 30 days and two years before the event) of incretin based drugs was significantly associated with an increased risk of acute pancreatitis (odds ratio 2.24 (95\% confidence interval 1.36 to 3.68 ) and 2.01 (1.37 to 3.18), respectively). The fact that the risk remained in recent users, however, potentially signals bias related to confounding by indication. Indeed, the comparator group in that study consisted of any antidiabetes drug, which included a mix of preferred treatments such as metformin, second line treatments, and third and fourth line treatments such as insulin. As incretin based drugs are typically second to third line drugs ${ }^{2}$ and the risk of acute pancreatitis increases with type 2 diabetes and possibly with duration of disease, ${ }^{40-42}$ it is imperative that they are compared with drugs used at the same or a similar stage of diabetes, otherwise this would introduce a time lag bias. ${ }^{43}$ It is for this reason that our primary comparator group consisted of sulfonylurea users, which we believe is the clinically most appropriate comparator. In sensitivity analyses, we compared users of incretin based drugs with alternate comparators-namely, insulin and metformin. While both 
analyses yielded non-significant results, interestingly, the hazard ratios for insulin and metformin were 0.79 and 1.52 ,

respectively. The difference in the magnitude of these hazard ratios is consistent with the hypothesis that insulin users are at a higher risk of acute pancreatitis than metformin users, and thus the use of these drugs likely reflects the underlying severity of the disease. These analyses underline the importance of choosing an appropriate comparator, which future studies will need to consider.

\section{Strengths and limitations of this study}

The strengths of our study include the use of a large population based cohort of patients with type 2 diabetes followed for up to 25 years in CPRD, a database that has been shown to be representative of the UK general population. Moreover, the CPRD allowed us to consider important potential confounders (such as BMI, excessive alcohol use, and $\mathrm{HbA1c}$ ), which were included along with over 500 variables in the hdPS model.$^{44}$ In contrast with standard propensity score methods, the hdPS method emperically selects variables based on their prevalence and potential for confounding. ${ }^{29}$ This particularity allows for the inclusion of potential confounders that might not been considered a priori. Finally, using a primary cohort of patients newly treated with non-insulin drugs allowed us to accurately calculate the duration of treated diabetes before cohort entry, a potentially major confounder.

This study does have some limitations. Drug exposures recorded in the CPRD are from prescriptions written by general practitioners, and the database does not record prescriptions written by specialists. We do not believe, however, that such missing information was differential between patients exposed to incretin based drugs and the active comparator group. Moreover, we do not know if patients complied with the treatment, although renewal of prescriptions is probably a good indicator of drug use. To our knowledge, the validity of the recording of acute pancreatitis in the CPRD has not been formerly validated, although it has been used previously in another unrelated study. ${ }^{42}$ For this reason, we used the HES database as an additional data source to capture this outcome, which probably maximised the validity of the case ascertainment. Another limitation relates to the rarity of acute pancreatitis, which probably limited some of the secondary analyses by duration of use and sex. It is important to note, however, that our study had $98 \%$ power to detect a large effect, such as a hazard ratio of 2.0, one similar in magnitude as in the study reporting an association. ${ }^{23}$ A potentially important confounder is hypertriglyceridaemia, a known risk factor for pancreatitis. Use of results of laboratory tests to adjust for this variable was not possible as they were missing for a large proportion of patients. The use of fibrates (a proxy for treated hypertriglyceridaemia), however, was included in the hdPS score estimation. Although our results remained consistent after the models were ajusted for tenths of hdPS, residual confounding is always possible, as it is with any observational study. Furthermore, the results remained somewhat consistent when we compared incretin based drugs with other classes of antidiabetes drugs. This is especially relevant as past use of sulfonylureas has been suspected to increase the risk of acute pancreatitis compared with other antidiabetes drugs. ${ }^{40}$ In a sensitivity analysis, we obtained consistent results after excluding patients who used sulfonylureas before cohort entry. Finally, given the limited number of events, we could not investigate the effect of dose of incretin based drugs on the outcome.

\section{Conclusions and implications}

In summary, the results of our population based study suggest that, compared with use of sulfonylureas, the use of incretin based drugs is not associated with an increased risk of acute pancreatitis among patients with type 2 diabetes. While our study provides some reassurance to physicians and patients using these drugs, the upper bound of the confidence interval for the hazard ratio suggests that we cannot preclude a modest increase in risk. Additional large well conducted observational studies are needed to confirm our findings.

Contributors: All authors participated in the study design. SS acquired the data. JLF, LA, and VP did the statistical analyses. JLF wrote the initial draft, and all authors critically revised the manuscript. SS is guarantor.

Funding: This study was funded in part by research grants from the Canadian Institute of Health Research (CIHR), and the Canada Foundation for Innovation. The funding sources had no role in the design, analysis, or interpretation of the results, and thus the authors were independent from the funding sources. J-LF receives a grant from the Société Francophone du Diabète, LA is the recipient of a Chercheur-Boursier career award from the Fonds de recherche du Québec-Santé, and SS is the recipient of the James McGill Chair award. Competing interests: All authors have completed the ICMJE uniform disclosure form at www.icmje.org/coi_disclosure.pdf (available on request from the corresponding author) and declare: database acquisitions were funded by the Canadian Institute of Health Research (CIHR) and the Canada Foundation for Innovation; SS has received research grants, participated in advisory board meetings and/or as a speaker at conferences for AstraZeneca, Bayer, Boehringer-Ingelheim, Bristol-Myers-Squibb, Merck, and Novartis, all of which except Bayer are manufacturers of incretin based drugs, though none of these activities were related to diabetes or incretins, with the exception of a single participation in a mock advisory panel for Bristol-Myers-Squibb. Ethical approval: The study protocol was approved by the independent scientific advisory committee of the Clinical Practice Research Datalink and by the research ethics board of the Jewish General Hospital, Montreal, Canada.

\section{Data sharing: No additional data available.}

Transparency declaration: SS affirms that this manuscript is an honest, accurate, and transparent account of the study being reported; that no important aspects of the study have been omitted; and that any discrepancies from the study as planned (and, if relevant, registered) have been explained.

1 Drucker DJ. Biological actions and therapeutic potential of the glucagon-like peptides. Gastroenterology 2002;122:531-44.

2 Inzucchi SE, Bergenstal RM, Buse JB, Diamant M, Ferrannini E, Nauck M, et al. Management of hyperglycaemia in type 2 diabetes: a patient-centered approach. Position statement of the American Diabetes Association (ADA) and the European Association statement of the American Diabetes Association (ADA) and the Europs
for the Study of Diabetes (EASD). Diabetologia 2012;55:1577-96.

3 Elashoff M, Matveyenko AV, Gier B, Elashoff R, Butler PC. Pancreatitis, pancreatic, and thyroid cancer with glucagon-like peptide-1-based therapies. Gastroenterology 2011;141:150-6.

4 Raschi E, Piccinni C, Poluzzi E, Marchesini G, De Ponti F. The association of pancreatitis with antidiabetic drug use: gaining insight through the FDA pharmacovigilance database. Acta Diabetol 2013;50:569-77.

5 Institute for Safe Medication Practices. Perspectives on GLP-1 agents for diabetes. 2013 www.ismp.org/QuarterWatch/pdfs/2012Q3.pdf.

6 Faillie JL, Babai S, Crepin S, Bres V, Laroche ML, Le Louet H, et al. Pancreatitis associated with the use of GLP-1 analogs and DPP-4 inhibitors: a case/non-case study from the French Pharmacovigilance Database. Acta Diabetol 2013;doi:10.1007/s00592-013-05440 .

7 US Food and Drug Administration. Information for healthcare professionals: exenatide (marketed as Byetta)-8/2008 update. www.fda.gov/Drugs/DrugSafety/ PostmarketDrugSafetyInformationforPatientsandProviders/ucm124713.htm.

8 US Food and Drug Administration. Safety requirements for Victoza (liraglutide). www.fda. gov/Drugs/DrugSafety/PostmarketDrugSafetylnformationforPatientsandProviders/ ucm198543.htm.

9 US Food and Drug Administration. Information for healthcare professionals-acute pancreatitis and sitagliptin (marketed as Januvia and Janumet). September 25, 2009 www.fda.gov/Drugs/DrugSafety/PostmarketDrugSafetyInformationforPatientsandProviders/ DrugSafetylnformationforHeathcareProfessionals/ucm183764.htm. 


\section{What is already known on this topic}

The occurrence of acute pancreatitis associated with the use of glucagon-like peptide 1 analogues and dipeptidyl peptidase- 4 inhibitors is controversial, with conflicting data from preclinical animal studies, randomised controlled trials, adverse event databases, and observational studies

Additional observational studies are needed to assess whether these drugs are associated with acute pancreatitis

\section{What this study adds}

Compared with sulfonylureas, the use incretin based drugs was not associated with an increased risk of acute pancreatitis in a population based cohort study from the Clinical Practice Research Datalink

While these null results are reassuring, large well conducted population based studies are needed to rule out a modest increased risk of acute pancreatitis associated with these drugs

10 European Medicines Agency. Januvia (sitagliptin). Summaries of product characteristics. 2012. www.ema.europa.eu/docs/en_GB/document_library/EPAR - Product_Information/ human/000722/WC500039054.pdf.

11 European Medicines Agency. Galvus (vildagliptin). Summaries of product characteristics. 2012. www.ema.europa.eu/docs/en_GB/document_library/EPAR_-_Product_Information/ human/000771/WC500020327.pdf

12 European Medicines Agency. Onglyza (saxagliptin). Summaries of product characteristics. 2012. www.ema.europa.eu/docs/en_GB/document_library/EPAR_-_Product_Information/ human/001039/WC500044316.pdt.

13 European Medicines Agency. Byetta (exenatide). Summaries of product characteristics. 2012. www.ema.europa.eu/docs/en_GB/document_library/EPAR_-_Product_Information/ human/000698/WC500051845.pdf

14 European Medicines Agency. Onglyza (liraglutide). Summaries of product characteristics. 2012. www.ema.europa.eu/docs/en_GB/document_library/EPAR__Product_Information/ human/001026/WC500050017.pdf

15 Dore DD, Bloomgren GL, Wenten M, Hoffman C, Clifford CR, Quinn SG, et al. A cohort study of acute pancreatitis in relation to exenatide use. Diabetes Obes Metab 2011;13:559-66.

16 Dore DD, Seeger JD, Arnold Chan K. Use of a claims-based active drug safety surveillance system to assess the risk of acute pancreatitis with exenatide or sitagliptin compared to metformin or glyburide. Curr Med Res Opin 2009;25:1019-27.

17 Eurich DT, Simpson S, Senthilselvan A, Asche CV, Sandhu-Minhas JK, McAlister FA. Comparative safety and effectiveness of sitagliptin in patients with type 2 diabetes: retrospective population based cohort study. BMJ 2013;346:\{2267.

18 Funch D, Gydesen H, Tornoe K, Major-Pedersen A, Chan KA. A prospective, claims-based assessment of the risk of pancreatitis and pancreatic cancer with liraglutide compared to other antidiabetic drugs. Diabetes Obes Metab 2014:16:273-5.

19 Garg R, Chen W, Pendergrass M. Acute pancreatitis in type 2 diabetes treated with exenatide or sitagliptin: a retrospective observational pharmacy claims analysis. Diabetes Care 2010;33:2349-54.

20 Romley JA, Goldman DP, Solomon M, McFadden D, Peters AL. Exenatide therapy and the risk of pancreatitis and pancreatic cancer in a privately insured population. Diabetes Technol Ther 2012;14:904-11.

21 Wenten M, Gaebler JA, Hussein M, Pelletier EM, Smith DB, Girase P, et al. Relative risk of acute pancreatitis in initiators of exenatide twice daily compared with other anti-diabetic medication: a follow-up study. Diabet Med 2012;29:1412-8.

22 Giorda C, Picariello R, Nada E, Tartaglino B, Marafetti L, Costa G, et al. Incretin therapies and risk of hospital admission for acute pancreatitis in an unselected population of European patients with type 2 diabetes: a case-control study. Lancet Diabetes Endocrinol 2014;2:111-5.

23 Singh S, Chang HY, Richards TM, Weiner JP, Clark JM, Segal JB. Glucagon like peptide 1 -based therapies and risk of hospitalization for acute pancreatitis in type 2 diabetes mellitus: a population-based matched case-control study. JAMA Intern Med 2013;173:534-9

24 Cohen D. European drugs agency clashes with scientists over safety of GLP-1 drugs. BMJ 2013;347:44838.

25 Cohen D. FDA is to assess data linking type 2 diabetes drugs with pancreatitis. BMJ 2013:346:f1808.

26 Garcia Rodriguez LA, Perez Gutthann S. Use of the UK general practice research database for pharmacoepidemiology. Br J Clin Pharmacol 1998;45:419-25.

27 Herrett E, Thomas SL, Schoonen WM, Smeeth L, Hall AJ. Validation and validity of diagnoses in the General Practice Research Database: a systematic review. Br J Clin Pharmacol 2010:69:4-14.

28 Laferrere B, Heshka S, Wang K, Khan Y, McGinty J, Teixeira J, et al. Incretin levels and effect are markedly enhanced 1 month after Roux-en- $Y$ gastric bypass surgery in obese patients with type 2 diabetes. Diabetes Care 2007;30:1709-16.
29 Schneeweiss S, Rassen JA, Glynn RJ, Avorn J, Mogun H, Brookhart MA. High-dimensional propensity score adjustment in studies of treatment effects using health care claims data. Epidemiology 2009;20:512-22.

30 Huberman M, Langholz B. Application of the missing-indicator method in matched case-control studies with incomplete data. Am J Epidemiol 1999;150:1340-5.

31 Hosmer DW, Lemeshow S, eds. Applied logistic regression. 2nd ed. Wiley, 2000

32 Parsons LS. Reducing bias in a propensity score matched-pair sample using greedy matching techniques. Proceedings of the Twenty-Sixth Annual SAS Users Group International Conference, Cary, NC, 2001. www2.sas.com/proceedings/sugi26/p214-26. pdf.

33 Butler AE, Campbell-Thompson M, Gurlo T, Dawson DW, Atkinson M, Butler PC. Marked expansion of exocrine and endocrine pancreas with incretin therapy in humans with increased exocrine pancreas dysplasia and the potential for glucagon-producing neuroendocrine tumors. Diabetes 2013;62:2595-604.

34 Butler PC, Elashoff M, Elashoff R, Gale EA. A Critical analysis of the clinical use of incretin-based therapies: are the GLP-1 therapies safe? Diabetes Care 2013:36:2118-25.

35 Drucker DJ. Incretin action in the pancreas: potential promise, possible perils, and pathological pitfalls. Diabetes 2013;62:3316-23.

36 Monami M, Dicembrini I, Mannucci E. Dipeptidyl peptidase-4 inhibitors and pancreatitis risk: a meta-analysis of randomized clinical trials. Diabetes Obes Metab 2014;16:48-56.

37 Monami M, Dicembrini I, Nardini C, Fiordelli I, Mannucci E. Glucagon-like peptide-1 receptor agonists and pancreatitis: a meta-analysis of randomized clinical trials. Diabetes Res Clin Pract 2014:1-3:269-75.

38 Scirica BM, Bhatt DL, Braunwald E, Steg PG, Davidson J, Hirshberg B, et al. Saxagliptin and cardiovascular outcomes in patients with type 2 diabetes mellitus. N Engl J Med 2013;369:1317-26

39 White WB, Cannon CP, Heller SR, Nissen SE, Bergenstal RM, Bakris GL, et al. Alogliptin after acute coronary syndrome in patients with type 2 diabetes. $N$ Engl $\mathrm{J} \mathrm{Med}$ 2013:369:1327-35.

40 Gonzalez-Perez A, Schlienger RG, Rodriguez LA. Acute pancreatitis in association with type 2 diabetes and antidiabetic drugs: a population-based cohort study. Diabetes Care 2010;33:2580-5

41 Noel RA, Braun DK, Patterson RE, Bloomgren GL. Increased risk of acute pancreatitis and biliary disease observed in patients with type 2 diabetes: a retrospective cohort study. Diabetes Care 2009;32:834-8.

42 Girman CJ, Kou TD, Cai B, Alexander CM, O'Neill EA, Williams-Herman DE, et al. Patients with type 2 diabetes mellitus have higher risk for acute pancreatitis compared with those without diabetes. Diabetes Obes Metab 2010;12:766-71.

43 Suissa S, Azoulay L. Metformin and the risk of cancer: time-related biases in observational studies. Diabetes Care 2012;35:2665-73.

44 Garbe E, Kloss S, Suling M, Pigeot I, Schneeweiss S. High-dimensional versus conventional propensity scores in a comparative effectiveness study of coxibs and reduced upper gastrointestinal complications. Eur J Clin Pharmacol 2013;69:549-57.

Accepted: 06 April 2014

\section{Cite this as: BMJ 2014;348:g2780}

This is an Open Access article distributed in accordance with the Creative Commons Attribution Non Commercial (CC BY-NC 3.0) license, which permits others to distribute, remix, adapt, build upon this work non-commercially, and license their derivative works on different terms, provided the original work is properly cited and the use is non-commercial. See: http://creativecommons.org/licenses/by-nc/3.0/. 


\section{Tables}

Table 1| Baseline characteristics of users of incretin based drugs and sulfonylureas. Figures are numbers (percentage) of users unless specified otherwise

\begin{tabular}{|c|c|c|}
\hline Baseline characteristics & Incretin based drug users ( $n=20748)$ & Sulfonylurea users $(n=51712)$ \\
\hline Mean (SD) age (years) & $56.0(11.3)$ & $62.9(12.9)$ \\
\hline Men & $11897(57.3)$ & $30091(58.2)$ \\
\hline \multicolumn{3}{|l|}{ Year of cohort entry: } \\
\hline 2007 & $273(1.3)$ & $25466(49.2)$ \\
\hline 2008 & $1427(6.9)$ & $5295(10.2)$ \\
\hline 2009 & $3459(16.7)$ & $5620(10.9)$ \\
\hline 2010 & $5449(26.3)$ & $5360(10.4)$ \\
\hline 2011 & $5121(24.7)$ & $5130(9.9)$ \\
\hline 2012 & $4647(22.4)$ & $4412(8.5)$ \\
\hline 2013 & $372(1.8)$ & $429(0.8)$ \\
\hline Mean (SD) duration of treated diabetes (years) & $5.2(3.7)$ & $3.4(3.2)$ \\
\hline Excessive alcohol use & $3711(17.9)$ & $7627(14.7)$ \\
\hline \multicolumn{3}{|l|}{ Smoking status: } \\
\hline Ever & $13331(64.3)$ & $32624(63.1)$ \\
\hline Never & $7408(35.7)$ & $18926(36.6)$ \\
\hline Unknown & $9(0.04)$ & $162(0.3)$ \\
\hline \multicolumn{3}{|l|}{ BMI categories: } \\
\hline$\leq 25$ & $1326(6.4)$ & $9167(17.7)$ \\
\hline $25-30$ & $4631(22.3)$ & $18214(35.2)$ \\
\hline$>30$ & $14728(71.0)$ & $23500(45.4)$ \\
\hline Unknown & $63(0.3)$ & $831(1.6)$ \\
\hline \multicolumn{3}{|l|}{ HbA1c categories: } \\
\hline$\leq 7 \%$ & $1710(8.2)$ & $12,610(24.4)$ \\
\hline $7-8 \%$ & $5925(28.6)$ & $14837(28.7)$ \\
\hline$>8 \%$ & $12950(62.4)$ & $21152(40.9)$ \\
\hline Unknown & $163(0.8)$ & $3113(6.0)$ \\
\hline Previous pancreatitis* & $283(1.4)$ & $864(1.7)$ \\
\hline History of gallstones & $1272(6.1)$ & $2818(5.4)$ \\
\hline \multicolumn{3}{|l|}{ Antidiabetes drugs before cohort entry†: } \\
\hline Metformin & $18688(90.1)$ & $35865(69.4)$ \\
\hline Sulfonylureas & $11931(57.5)$ & $21165(40.9)$ \\
\hline Mean (SD) duration of use (years) & $1.2(2.0)$ & $0.9(1.7)$ \\
\hline Insulins & $1372(6.6)$ & $1233(2.4)$ \\
\hline Thiazolidinediones & $4986(24.0)$ & $6305(12.2)$ \\
\hline Other antidiabetes drugs & $353(1.7)$ & $349(0.7)$ \\
\hline
\end{tabular}

$\mathrm{BMI}=$ body mass index; $\mathrm{HbA} 1 \mathrm{C}=$ haemoglobin $\mathrm{A} 1 \mathrm{c}$.

*Either acute or chronic pancreatitis.

†Measured in year before cohort entry. 
Table 2/ Crude and adjusted hazard ratios for acute pancreatitis associated with use of incretin based drugs compared with sulfonylureas *

\begin{tabular}{lccccccc} 
& & & & & \multicolumn{2}{c}{ HR (95\% Cl) } \\
\cline { 5 - 8 } Exposure group & No of patients & Events & Person years & Incidence rate (per $\mathbf{1 0 0 0}$ person years) & Crude & Adjustedt \\
Sulfonylureas & 51712 & 119 & 80815 & $1.47(1.23$ to 1.76$)$ & 1.00 (reference) & 1.00 (reference) \\
\hline Incretin based drugs & 20748 & 27 & 18682 & $1.45(0.99$ to 2.11$)$ & 0.82 (0.54 to 1.25$)$ & 1.00 (0.59 to 1.70$)$ \\
\hline
\end{tabular}

*Analysis based on as treated exposure definition.

†Adjusted for tenths of high dimensional propensity score and year of cohort entry. 
Table 3| Crude and adjusted hazard ratios for acute pancreatitis associated with use of incretin based drugs compared with sulfonylureas according to duration of use and sex*

\begin{tabular}{|c|c|c|c|c|c|c|}
\hline \multirow[b]{2}{*}{ Exposure group } & \multirow[b]{2}{*}{ No of patients } & \multirow[b]{2}{*}{ Events } & \multirow[b]{2}{*}{ Person years } & \multirow[b]{2}{*}{ Incidence rate (per 1000 person years) } & \multicolumn{2}{|c|}{ HR $(95 \% \mathrm{Cl})$} \\
\hline & & & & & Crude & Adjusted $†$ \\
\hline \multicolumn{7}{|c|}{ Time interval of duration of use } \\
\hline \multicolumn{7}{|l|}{ 0-1 years: } \\
\hline Sulfonylureas & 51712 & 74 & 35502 & 2.08 (1.66 to 2.62$)$ & 1.00 (reference) & 1.00 (reference) \\
\hline Incretin based drugs & 20748 & 21 & 11955 & 1.76 (1.15 to 2.69$)$ & $0.84(0.52$ to 1.37$)$ & 1.08 (0.57 to 2.03$)$ \\
\hline \multicolumn{7}{|l|}{ 1-2 years: } \\
\hline Sulfonylureas & 24412 & 24 & 18894 & $1.27(0.85$ to 1.90$)$ & 1.00 (reference) & 1.00 (reference) \\
\hline Incretin based drugs & 6814 & 4 & 4517 & $0.89(0.33$ to 2.36$)$ & $0.68(0.24$ to 1.96$)$ & $1.06(0.31$ to 3.60$)$ \\
\hline \multicolumn{7}{|l|}{ >2 years: } \\
\hline Sulfonylureas & 14659 & 21 & 26312 & 0.80 (0.52 to 1.22$)$ & 1.00 (reference) & 1.00 (reference) \\
\hline Incretin based drugs & 2824 & 2 & 2183 & 0.92 (0.23 to 3.66$)$ & $0.97(0.22$ to 4.27$)$ & 0.51 (0.09 to 2.86$)$ \\
\hline \multicolumn{7}{|l|}{ Sex } \\
\hline \multicolumn{7}{|l|}{ Women: } \\
\hline Sulfonylureas & 21621 & 43 & 33526 & 1.28 (0.95 to 1.73$)$ & 1.00 (reference) & 1.00 (reference) \\
\hline Incretin based drugs & 8851 & 5 & 7629 & $0.66(0.27$ to 1.57$)$ & $0.42(0.17$ to 1.07$)$ & $0.45(0.15$ to 1.31$)$ \\
\hline \multicolumn{7}{|l|}{ Men: } \\
\hline Sulfonylureas & 30091 & 76 & 47289 & 1.61 (1.28 to 2.01 ) & 1.00 (reference) & 1.00 (reference) \\
\hline Incretin based drugs & 11897 & 22 & 11053 & 1.99 (1.31 to 3.02$)$ & $1.04(0.65$ to 1.69$)$ & $1.41(0.75$ to 2.63$)$ \\
\hline
\end{tabular}

*Analysis based on as treated exposure definition.

†Adjusted for tenths of high dimensional propensity score and year of cohort entry. 


\section{Figures}

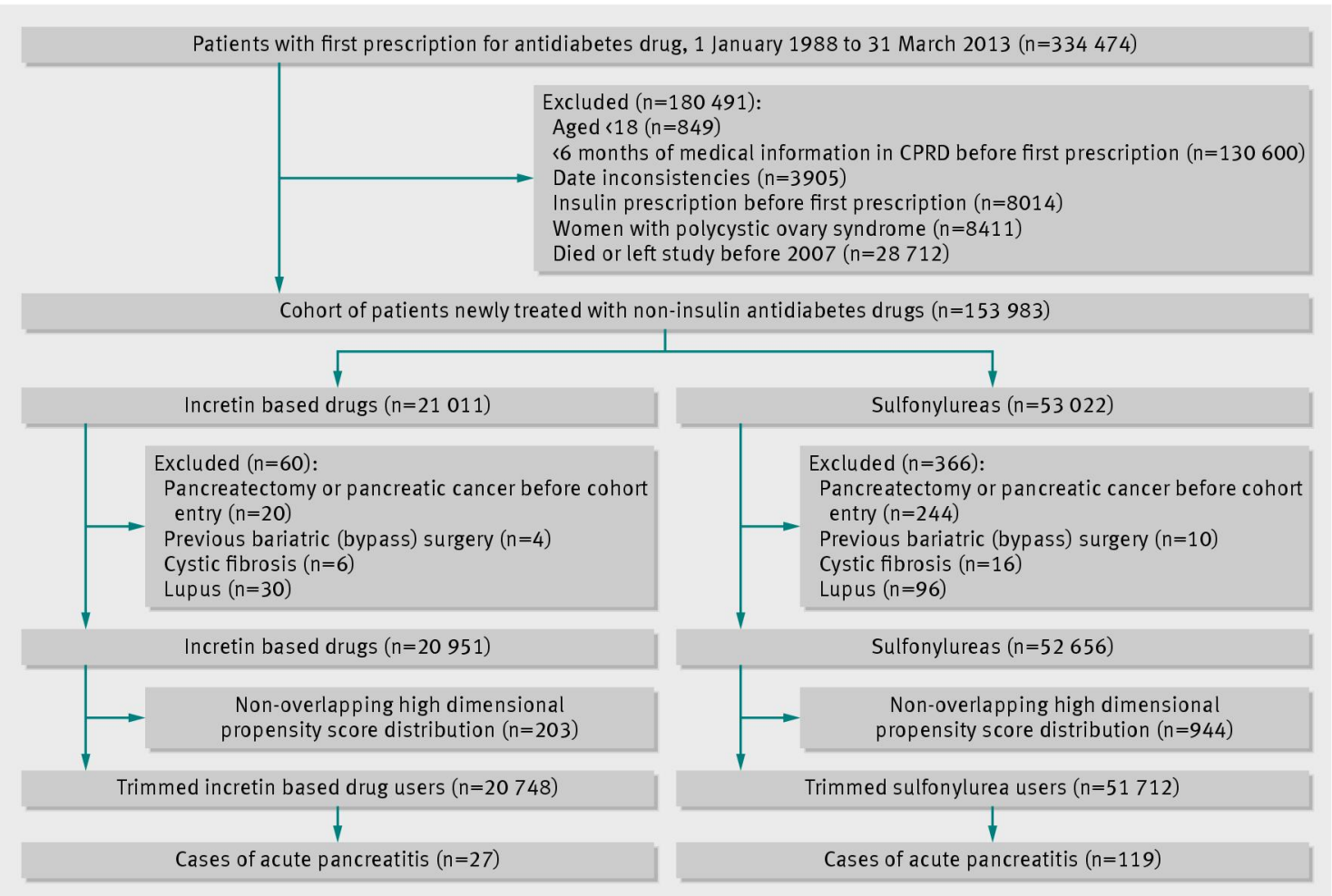

Fig 1 Flow of participants in cohort study of effect of incretin based drugs in patients with type 2 diabetes

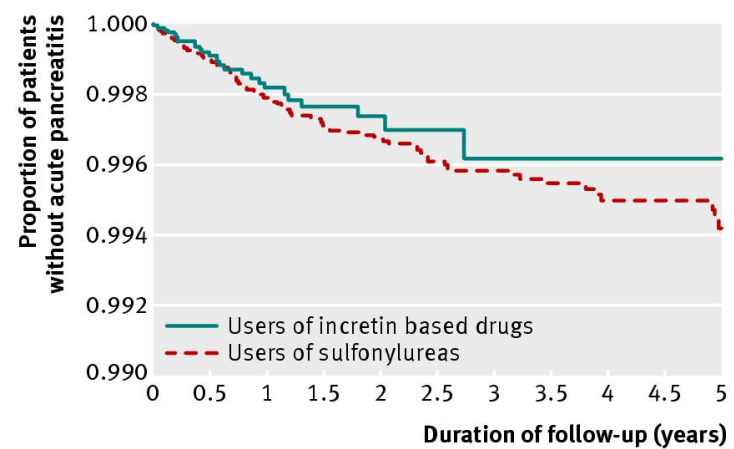

Fig 2 Kaplan-Meier curves for acute pancreatitis in users of incretins compared with users of sulfonylurea (log rank $\mathrm{P}=0.36$ ) 